\title{
The Application of Flipped Classroom in College English Teaching in the Era of Big Data
}

\author{
ZHENG Weiwei ${ }^{1, a}$ \\ ${ }^{1}$ Jilin Business and Technology College, Changchun City 130507,China \\ azhengweiwei@126.com
}

Keywords: Flipped classroom, college English teaching, innovative teaching

\begin{abstract}
With the popularity of the Internet and the use of mobile terminals, college English teaching has entered the era of big data. Big data era also puts forward new requirements for college English teaching at the same time, as well as new opportunities. College English teaching resources, teaching tools and evaluation means have greatly changed. Combining Moodle platform with flipped classroom can make college English teaching realize the personalized teaching and interaction. Flipped classroom as a new teaching mode, has been widely used in many western countries. At the same time, it has been accepted by the many Chinese teachers and students. Whether it should be applied in college English teaching and how to apply it has become the focus in the study of foreign language teaching in China. This research attempts to study the classroom theoretical framework to analyze the reasons and methods of flipped classroom in college English classroom. Flipped classroom advocates student-centered classroom teaching activities and at the same time, encourages students to become autonomous learners.
\end{abstract}

\section{The background of flipped classroom}

What is a flipped classroom? The flip teaching idea is firstly originated in a mountainous area school in the American state of Colorado --, "forest park" senior high school. In the spring of 2007, two of the school chemistry teachers Jon Bergmann and Aaron Sams began to use screen capture software to record PowerPoint presentations and the audio of the lecturer. In this way, those who cannot attend the class because of illness or other reasons can also make course content accordingly through watching the video. Later, they tried to record all the courses as students "homework", then answered the concept and homework in class that the student do not understand after class. These recorded course began to spread on the Internet, the teachers began to use online audio materials in extracurricular counseling students, and the class time is for working together and understand the concepts and finish the homework. This is what we now discuss a hot topic in the origin of the flipped class. In the flipped classroom, in addition to the traditional reading exercises, homework, interactive exercises and PPT showing, teaching video and online learning materials are released to the student. Flipped class promotes the student as the main body of learning, students can watch teaching video at home, learn the rhythm completely by the students themselves according to their own actual situation. Different from previous online courses, flipped classroom includes classroom or laboratory environment of face-to-face teaching between teachers and students, students can discuss and apply in class what they learned in extra-curricular learning with questions. Flip the classroom allows teachers to present the classroom content in various styles and novel variety of forms; therefore it covers different ways of teaching and can meet the needs of different students. Flip classroom encourages students to become independent learners, and can help students apply in reality in the future work.

\section{The theoretical structure of flipped classroom}

The key part of flipped classroom learning mode is the information technology and autonomous learning, cooperative learning. In the process of flip classroom implementation of the class, the teacher use information technology, design the course and teaching activities for the students, let students learn in extracurricular autonomous to help students complete "meaning construction" of knowledge in the "dialogue" and "consultation" in the class. In general, flip class involves four 
main learning theories:

One is the master learning theory. The century in the early $70 \mathrm{~s}$, bloom mastery learning theory is proposed. So-called "mastery learning", is in the "all students can learn under the guidance of thought, on the basis of the collective teaching, class teaching system, supplemented by frequently, timely feedback, provide students with the required individualized assistance and required extra study time, so as to make the most of the students achieve the master standard stipulated in the curriculum goal. Under the theoretical guidance, provide materials, tools and support teachers, students set learning goal and control their learning time. The first student to finish homework before you hand it in to correct. Before implementing flip classroom mastery learning theory in most schools are not very practical. According to different levels of students issued by different levels of curriculum content is unlikely. Test can't reflect the actual effect, because learning faster, the result good students to try to schedule a slower classmates.

The second is the constructivism learning theory. Constructivism is the school of thought in cognitive psychology a branch. Constructivism theory is an important concept of schemata, schema refers to an individual's perception to the world understand and way of thinking can also see it as a psychological activity framework or structure. Constructivism theory is that the production of human knowledge and meaning from their experience and the interaction of ideas. Piaget's constructivist learning theory has wide influence learning and education theory, is the underlying theme of many education reform. With different skills and learning background can learners in the learning task and discuss cooperation, so as to reach a consensus in a particular field.(1992) Duffy and Janssen were, constructivism theory advocates student-centered learning under teacher's guidance. In flip the design process of the classroom, teachers can according to the characteristics of the students in different subjects and different design with students as the center of a variety of classroom activities.

The third is the met cognitive theory. According to the American psychologist, palaver (j. h. Flavell) point of view, and met cognition is the cognition of cognition, specifically, is about personal cognitive process of knowledge and the ability to regulate these processes: knowledge and control of thinking and learning activities. Met cognition includes met cognitive knowledge and met cognitive control. Flip the success of class depends on whether students can carefully study on the traditional classroom teachers knowledge of teaching and classroom discussion the internalization of knowledge.

The forth is reciprocal determinism. Reciprocal determinism is presented by the psychologist Albert bandura. Bandura's reciprocal determinism is based on the absorption of behaviorism, humanism and the merits of the relevant part of the cognitive psychology and critically pointed out that, on the basis of their respective deficiency, with their distinctive characteristics. Bandura pointed out: "behavior, human factors, environmental factors are actually as determinants of interconnection and interaction effect". Reciproca1 this concept is defined as the interaction between what "interaction", the determinism is defined as "things affect product". Reciprocal determinism believes that a person's behavior and personal factors and social environment influence each other. Environment, and behavior and the relationship between each other, is a kind of interactive decision process.

\section{The demands of English teaching reform in the era of big data}

The new era has put forward the following several demands:

1 , the personalized teaching

Under the background of big data era, first of all, the role of teacher has changed into learning guider, the blazers and organizer, teachers need to understand the students' cognitive style, learning objectives, learning methods and etc., and provide personalized guidance according to the different needs of students. Secondly, the roles of students also changed. The student is the center of learning, students have more personal development space. Under the background of big data era, students can learn on my own time, choose the learning content, control learning process. At the same time, students need to know their responsibilities in the learning process. Students have a lot of autonomy, 
but also need strong self monitoring and self management ability. The modern university education, emphasizing on the students' personalized development and cultivate autonomous learning ability. Personalized education to students' learning potential maximum mining, help them achieve the biggest learning achievements.

2 , the teaching interaction

Big data provides the technical support for new teachers and students exchange model. Big data has gradually integrated into people's life with its characteristics of vast, high-speed, diversity. Big data era, the communication between teachers and students changed from the traditional teacher taught the unidirectional development authority to giving priority to students. Under the background big data era, communication between teachers and students no longer subject to space and time limitations. The students' subjectivity demands can be fully reflected; students have enough time and opportunity to interact with teachers, reflect the value of self exists, teachers and students as the main body of the teaching activities together. Students are no longer complete recipient but to obtain self existence.

\section{3 , learning depth}

The acquisition of learning process is divided into six levels, namely knowing, understanding, applying, analysis, synthesis and evaluation. Among them, knowing and grasping belong to the primary stage, namely mechanical memory of shallow learning period for knowledge. Applying, analysis, synthesis and evaluation belong to the advanced stage, namely on the depth of knowledge learning period. The traditional teaching activities are dominated by teachers, and students in the classroom feedback extremely limited. Although the traditional teaching method is beneficial to teachers imparting knowledge, students in the same class can also be a basic understanding and comprehend the theme of the classroom teaching, but it is bad for students to apply what they have learned. Students' mastery of knowledge only stays in the primary stage of learning, deep learning is learning mode on the depth of information processing. Students in the process of machining can be to actively constructing knowledge, using critical thinking mode, to actively explore and transformation of knowledge, effective migration. Deep learning to stimulate students' active learning motivation, potential interest in learning plays an important role.

4, The implementation reasons of flipped classroom study shows that the main reasons for teachers' teaching style and students' learning style are not harmonious leading to fewer and fewer students learn knowledge, more and more not interested in learning. It means either there will be the following two cases: teachers should make efforts to ensure that teachers' teaching style is coordinate with students learning methods; either teachers should rearrange to coordinate teaching style in order to appeal to different characteristics of students. The implementation of the class has the following nine reasons:

1. Students can learn at their own pace in the traditional classroom, the teacher show students how to solve the problem in the limited class hours. The teachers actively teach and students learn passively in class. For some students, the classes time just the right length. But for some already understand classroom materials, course content and students, the classroom problem class time is too slowly. In turn, for students who have learning difficulties, a short class time is not enough to make them understand the course content, the students are arranged to accept the guidance of the teacher after class or laborious recollection at home and try to understand the content of teaching teachers in the classroom.

2. The teacher can better understand the students in the traditional classroom, the teacher can through the students to hand in homework, not hand in your homework, failed to complete the homework, or to turn in homework is full of mistakes, determining the extent of students' learning and hard work. Class after the implementation of the transition, however, the teacher and students together with students in learning difficulties, at this point, the students learning problems is obvious, similar mistakes can nip in the bud. Teachers design classroom content not only, and encourage and listen to the students and broaden their horizons, and can establish a good relationship between teachers and students. At the same time, teachers can play the role of a model. These are the very important role and function. Flip the classroom, the teacher helps student to 
understand more, establish healthier, harmonious relationship between teachers and students.

3. Students can learn professional knowledge to a number of teachers teachers' teaching contents change frequently. For example, a term may taught by three teachers at the same course. If students were watching teaching video for a difficult concept to understand, can need not have been grappling with his teacher's explanation. But instead to watch other video courses teaching the same subject. Students found to watch video of the teacher is very different for their review, or from different angles to understand the concept of a more difficult to understand.

4. Teachers can learn from each other through flipped classroom. They can also design and modify the reverse course in any spare time to improve course evaluation and class notes, share their frustration and success in teaching. Based on the analysis of students' learning situation, they can note what kind of students is excellent in what fields. At the same time, they can watch teaching video from each other's in order to understand how colleagues teaching related concepts, to provide a new perspective for their teaching. In addition, teachers can also "visit" the teaching of each other, learn from each other and complement each other.

5. Class time can be effective and innovative uses in flip class, the teachers not only teach, they can spend more time in the classroom teaching and promote students' understanding of the knowledge. Teachers can make use of class time to communication, observation, guidance and help meaningfully with students. The lecture is carried in the form of watching the video at home. For now, the teachers can try new teaching methods in the classroom, including more practical activity and study oriented in solving the actual problem.

6. Parents can learn online courses. Most parents find it hard to recall the learned knowledge many years ago. When the children back to do homework, encounter problems, they refer to them when they feel frustrated and unable to help their children. They hope that teachers can help explain the homework problems for the children. In addition, in flipped classroom, children and parents can watch video teaching together and activate their knowledge skills.

7. Flipped classroom increases interactive communication between teachers and students. The flipped classroom can't replace the role of teacher like online classroom. In fact, flip increase the demand of teachers' individualized teaching, need to establish a good relationship between teachers and students, understand their students and design targeted teaching accordingly. More precisely, it is a kind of "hybrid" classroom.

8. Flip allow real differentiation, if a student showed similar needs more practice and practice, the teacher can like homework again. Students are now learning more flexible. In addition, for different levels of students, the reverse can also avoid some courses of oneness and banal.

9. The learning mode has entered into big data era, no matter when and where the students can get a lot of information through the network to learn. The era of big data, too much information might lead to more problems and challenges. As for the college students, they can decide the way in which they can use online self-study. Network technology has brought them great convenience to self-study.

\section{Summary}

In the era of big data, the innovation of college English teaching mode improves the teaching efficiency and learning efficiency, provides large capacity, diversification, fast speed and high value support data for teachers' teaching research, at the same time, continues to inspire students' interest in learning. We have now entered into the large data era, a lot of data and information technology has been applied in the university classroom, teachers are willing to carry out classroom teaching in the form of innovation, and flipped classroom is such an innovative structure, it moves the classroom into outsides through the information technology of the big data era, and moves the concept of understanding and assignments inside through learning activities. Flipped classroom is different form traditional classroom. In the traditional classroom, academic knowledge is transferred into every class through teachers' mind, teachers can explore the theme of the day through accurate, even entertainment way. For the flipped classroom, however, flipping and building online courses take several hours to prepare in advance. If you want to pursue high quality 
of video course, a lot of preparation work in advance is necessary. Online learning also needs constant progress and development, so, if flipped classroom reflects much advantages that traditional classroom can not have, teachers are likely to continue to adhere to it under heavy pressure and large preparations. If the flip classroom doesn't have investment of time, it will be easy to fade out education stage.

\section{References}

[1] J.G.Cai. Misunderstanding and prejudice: the key hindering the development of the college ESP teaching in China [J]. Foreign language teaching, 2013, (1).

[2] Z.Y.Chai. Considering of the use of MOOC for foreign language teaching --rituals, collaboration and innovation, value and impact[J]Foreign phone teaching, 2014, (2) : 32-37.

[3] X.L.Zhong, S.Q.Song, L.Z.Jiao. Teaching design research in informatization environment based on flipped classroom [J]. Open education research, 2013, (2).

[4] R.Q.Liu. Foreign language education and research in big data era[J]. Journal of contemporary foreign language study, 2014 (7).

[5] H.X.Wang. College English writing teaching reform in big data era [J]. Journal of modern distance education research. 2014 (3).

[6] J.L.Zhang, Y.Wang,B.H.Zhang. the research of flipped classroom teaching mode[J]. Journal of distance education, 2012, (4) : 46-51.

[7] G.Yang, W.Z.Yang, L.Chen. Ten excellent cases of flipped classroom[J] Information technology education of primary and secondary schools, 2012, (3) : 11-13. 